\title{
ARILASI 4-IODIDA ANISOL DENGAN $t$-BUTIL GERMANIUM MENGGUNAKAN KATALIS PALADIUM
}

Aldes Lesbani, Risfidian Mohadi dan Elfita.

Jurusan Kimia Fakultas Matematika Ilmu Pengetahuan Alam, Universitas Sriwijaya, Inderalaya, Sumatera Selatan

Corresponding author: aldeslesbani@yahoo.com

\begin{abstract}
Abstrak
Telah dilakukan arilasi 4-iodida anisol dengan t-butil germanium menggunakan katalis paladium dalam pelarut tetrahidrofuran dengan kondisi atmosfir argon. Produk hasil arilasi dikarakterisasi melalui penentuan titik leleh, pengukuran menggunakan kromatografi gas-spektrometer massa (GC-MS), dan resonansi magnetik inti (NMR) proton dan karbon.

Hasil penelitian menunjukkan bahwa produk arilasi adalah tris(4-metoksifenil)t-butil germanium (1) yang merupakan kristal putih dengan rendemen sebesar 35\%. Penentuan titik leleh senyawa (1) menghasilkan nilai sebesar $113,5-114,5{ }^{\circ} \mathrm{C}$ dengan nilai $\mathrm{m} / \mathrm{z}$ hasil pengukuran GC-MS sebesar 452 . Spektra ${ }^{1} \mathrm{H}$ NMR menunjukkan adanya tujuh puncak proton ekivalen dan spektra ${ }^{13} \mathrm{C}$ NMR menghasilkan empat puncak karbon ekivalen. Hasil keseluruhan karakterisasi menunjukkan kecocokan dengan senyawa (1).
\end{abstract}

Kata kunci: arilasi, 4-iodida anisol, t-butil germanium, paladium.

\section{Abstract}

The arylation of 4-iodo anisole with t-butyl germane using palladium as catalyst in tetrahydrofuran as a solvent in argon atmospheric condition was carried out. Product of arylation was characterized through determination of melting point, identification using gas chromatography-mass spectrometry (GC-MS), and nuclear magnetic resonance (NMR) proton and carbon.

The results showed that product of arylation is tris(4-methoxyphenyl)t-butyl germane (1) which has white crystals in 35\% yield. The determination of melting point compound (1) gave the value $113.5-114.5^{\circ} \mathrm{C}$ with $\mathrm{m} / \mathrm{z}$ 452 from GC-MS data. ${ }^{1} \mathrm{H} N M R$ spectrum resulted seven peaks of equivalent proton and ${ }^{13} \mathrm{C} N M R$ spectrum gave four peaks of equivalent carbon. All results of this characterization are appropriate with structure compound (1).

Keywords: arylation, 4-iodo anisole, t-butyl germane, palladium.

\section{Pendahuluan}

Arilasi merupakan salah satu reaksi yang terus dikembangkan hingga saat ini [1]. Salah satu alasan pengembangan reaksi arilasi yakni penggabungan rantai karbon-karbon yang mengandung gugus aril. Penggabungan rantai karbon-karbon secara umum dilakukan dengan reaksi kopling dengan penggunaan katalis [2]. Beberapa katalis yang umum digunakan dalam reaksi kopling adalah senyawa paladium dan platina $[3,4]$. walaupun kedua senyawa tersebut relatif mahal akan tetapi keunggulannya dalam merangkai rantai karbon-karbon telah teruji dalam banyak reaksi kimia. Keuntungan yang diperoleh dari reaksi arilasi yakni penemuan senyawasenyawa baru yang mempunyai sifat-sifat yang unik yang dapat dimanfaatkan untuk berbagai kepentingan. Disamping itu karena sintesis senyawa-senyawa baru sangat susah untuk dilakukan karena proses yang panjang maka dengan arilasi yang merupakan bagian dari reaksi kopling pembentukan produk dari reaktan dapat dipermudah karena tahap reaksi yang lebih singkat.

Lesbani et.al telah melaporkan reaksi arilasi berbagai gugus aril iodida dengan organosilika [5]. Reaksi ini telah diaplikasikan bagi sintesis pestisida yang mengandung gugus silika dengan tahap reaksi yang lebih pendek dibanding metode konvensional [6]. Sifat unik dari produk arilasi diteliti oleh Lesbani, et.al. yang mendapatkan senyawa yang mempunyai sifat fotoluminescence yang khas dengan warna biru-ungu [7]. Sifat ini muncul karena organosilika yang digunakan yakni 
tris(trimetilsilil)silan yang mempunyai geometri molekul yang meruah (bulky). Selain dengan menggunakan organosilika yang merupakan unsur grup 14 maka dapat dipula dilakukan arilasi dengan menggunakan organogermanium dari unsur grup yang sama [8]. Hal ini dikarenakan silika dan germanium memiliki sifat-sifat kimia yang mirip dengan konfigurasi elektron terluar yang mirip pula [9]. Lesbani, et.al. [5] melaporkan bahwa organogermanium yang berhasil diarilasi yakni $t$-butil germanium dengan senyawa aril yakni 2-iodida thiophen (rendemen 52\%), 3-iodida thiophen (rendemen 47\%), 4-iodida thioanisol (rendemen 46\%) serta $n$-butil germanium dengan 4-iodida anisol sebagai senyawa aril (rendemen 20\%). Penggunaan 4-iodida anisol sebagai senyawa aril dengan $t$-butil germanium belum dilaporkan dalam penelitian tersebut. Pada penelitian ini dilaporkan reaksi arilasi 4-iodida anisol dengan $t$-butil germanium menggunakan katalis paladium.

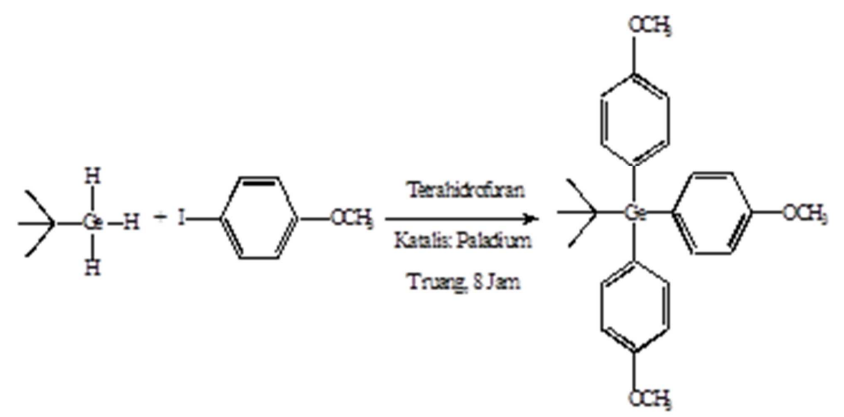

(1)
Gambar 1

Reaksi arilasi 4-iodida anisol dengan $t$-butil germanium membentuk tris(4-metoksifenil)t-butil germanium (1).

\section{Metodologi Penelitian}

\subsection{Alat dan Bahan}

Peralatan yang digunakan dalam penelitian ini meliputi labu Schlenk ukuran $100 \mathrm{~mL}$, syringe ukuran $5 \mathrm{~mL}$ dan $10 \mathrm{~mL}$, pipet tetes, chamber kromatografi, pompa vakum, rubber septum, pengaduk magnetik, corong pisah, rotary evaporator, dan gelas ukur. Peralatan analisis meliputi melting point Fischer Jones, spektrometer NMR Jeol ${ }^{1} \mathrm{H}$ dan ${ }^{13} \mathrm{C}$ dengan frekuensi masing-masing $500 \mathrm{MHz}$ dan 125 $\mathrm{MHz}$, kromatografi gas-spektrometer massa (GC-MS) Shimadzu 2110 QP.

Bahan-bahan kimia yang dipergunakan dalam penelitian ini berkualitas analytical grade yang meliputi 4-iodida anisol, $t$-butil germanium, paladium tersier tributil fosfin, 1,4-diazabisiklo[2,2,2]oktan, tetrahidrofuran, gas argon, etil asetat, heksana, diklorometan, pelat kromatografi lapis tipis (KLT), serta akuades.

\subsection{Prosedur arilasi 4-iodida anisol dengan $t$ - butil germanium dan karakterisasinya}

Labu Schlenk berukuran $100 \mathrm{~mL}$ divakum selama 15 menit. Setelah proses vakum selesai, ke dalam labu Schlenk tersebut dimasukkan $3 \mathrm{mmol}$ 4-iodida anisol, $1 \mathrm{mmol} t$ butil germanium, 0,05 mmol paladium tersier tributil fosfin, $4,5 \mathrm{mmol} \quad 1,4-$ diazabisiklo[2,2,2]oktan, dan $3 \mathrm{~mL}$ tetrahidrofuran. Labu Schlenk ditutup dengan rubber septum dan dialiri gas argon menggunakan balon yang telah diisi gas argon. Reaksi dilakukan pada temperatur ruang selama 8 hari sambil terus diaduk dengan pengaduk magnetik. Pembentukan produk arilasi diamati dengan kromatografi lapis tipis (KLT) dengan eluen etil asetat:heksana (90:10).

Setelah teramati pembentukan produk pada pelat KLT maka reaksi dihentikan dengan penambahan $10 \mathrm{~mL}$ air. Campuran dimasukkan dalam corong pisah dan ditambahkan $15 \mathrm{~mL}$ diklorometan. Proses pemisahan dilakukan pada ekstrak pekat dengan menggunakan kromatografi kolom dengan fase diam silika gel dan eluen etil asetat. Padatan putih yang diperoleh direkristalisasi menggunakan metanol untuk didapatkan produk murni. Produk murni hasil rekristalisasi dikarakterisasi melalui penentuan titik leleh, pengukuran menggunakan ${ }^{1} \mathrm{H}$ dan ${ }^{13} \mathrm{C}$ NMR serta GC-MS. 


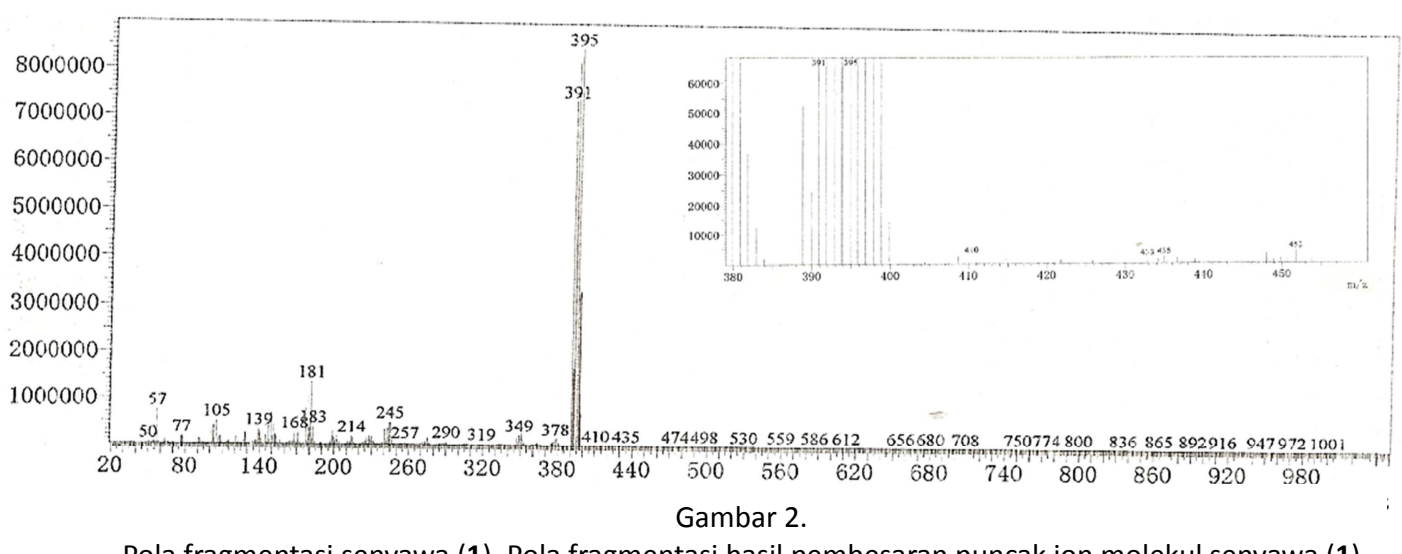

Pola fragmentasi senyawa (1). Pola fragmentasi hasil pembesaran puncak ion molekul senyawa (1) disajikan didalam kotak dimana $m / z 452$.

\section{Hasil dan Pembahasan}

Skama reaksi arilasi 4-iodida anisol dengan $t$-butil germanium dilakukan dalam kondisi inert menggunakan katalis paladium disajikan pada Gambar 1. Seperti terlihat pada Gambar 1, reaksi arilasi 4-iodida anisol dengan t-butil germanium dilakukan pada temperatur ruang selama 8 jam. Reaksi arilasi ini tergolong lambat bila dibandingkan dengan reaksi antara $t$-butil germanium dengan 2-iodida thiophen, 3-iodida thiophen maupun 4-iodida thioanisol seperti yang telah dilaporkan oleh Lesbani. et.al [5]. Rendemen yang terbentuk pada reaksi Gambar 1 diatas sebesar 35\% yang merupakan rendemen hasil isolasi senyawa (1) dalam keadaan murni setelah proses pemisahan dengan kromatografi kolom. Walaupun rendemen senyawa (1) yang terbentuk tidak terlalu besar akan tetapi senyawa (1) yang dihasilkan memiliki kemurnian yang tinggi sehingga proses rekristalisasi menggunakan metanol mudah untuk dilakukan. Kristal hasil rekristalisasi berupa padatan putih. Tahap awal identifikasi hasil reaksi arilasi dilakukan melalui penentuan titik leleh [10]. Hasil penentuan titik leleh terhadap Kristal putih yang merupakan senyawa (1) didapat sebesar $113,5-114,5{ }^{\circ} \mathrm{C}$. Perbedaan rentang titik leleh yang tidak terlalu besar ini mengindikasikan kemurnian senyawa (1). Untuk selanjutnya dilakukan identifikasi senyawa (1) hasil arilasi 4-iodida anisol dengan $t$-butil germanium menggunakan GC-MS. Pola fragmentasi massa senyawa (1) disajikan pada Gambar 2. Pada Gambar 2 terlihat bahwa senyawa (1) memiliki puncak ion molekul terbesar pada $m / z$ 452. Hasil awal pengukuran tidak memperlihatkan puncak ion molekul pada $m / z$

452. Akan tetapi hasil pembesaran puncak ion molekul pada pola fragmentasi senyawa (1) memperlihatkan adanya $\mathrm{m} / \mathrm{z} 452$ dengan intensitas yang sangat kecil seperti tersaji pada Gambar 2. Hasil perhitungan secara teoritik bobot molekul senyawa (1) didapat nilai 452 $\mathrm{g} / \mathrm{mol}$. Hal ini menunjukkan bahwa senyawa (1) merupakan senyawa hasil arilasi 4-iodida anisol dengan $t$-butil germanium. Puncak ion molekul pada Gambar 2 ditampilkan dalam dua gambar dikarenakan puncak ion molekul pada $\mathrm{m} / \mathrm{z} 452$ yang memiliki intensitas yang sangat rendah. Walaupun intensitas pada puncak ion molekul $\mathrm{m} / \mathrm{z} 452$ tidak tinggi akan tetapi adanya fragmentasi puncak ion molekul pada $\mathrm{m} / \mathrm{z} 395$ dengan intensitas 100\% menunjukkan adanya fragmentasi senyawa (1).

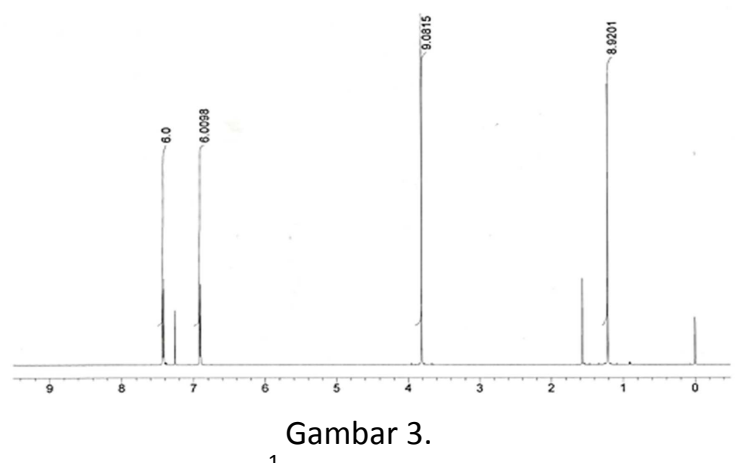

Spektra ${ }^{1} \mathrm{H}$ NMR senyawa (1). 


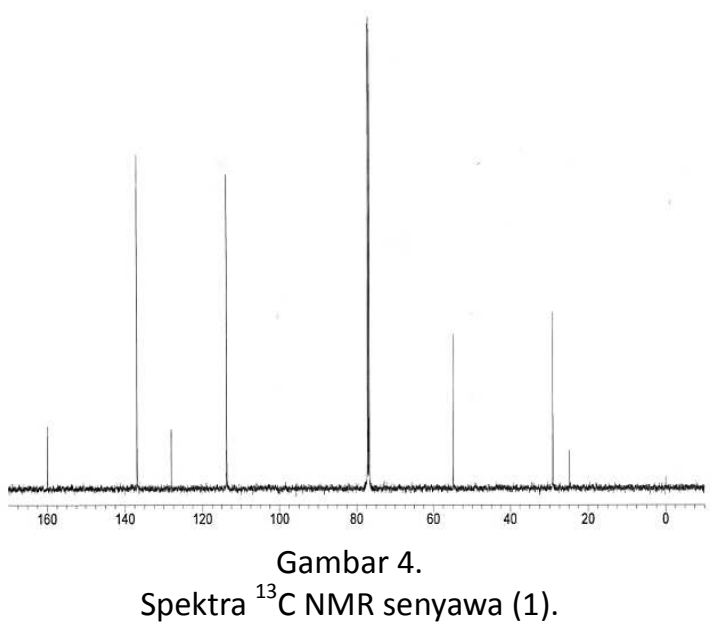

Puncak ion molekul pada $\mathrm{m} / \mathrm{z} 395$ tersebut mengindikasikan adanya fragmentasi dari gugus $t$-butil ( $m / z 57)$ pada senyawa (1) [11]. Selanjutnya dilakukan identifikasi menggunakan spektrofotometer NMR satu dimensi $\left({ }^{1} \mathrm{H}\right.$ dan $\left.{ }^{13} \mathrm{C}\right)$ [12] seperti yang tersaji pada Gambar 3 dan 4.

Pada spektra ${ }^{1} \mathrm{H}$ NMR seperti yang tersaji pada Gambar 3 terlihat bahwa adanya empat puncak-puncak proton ekivalen pada senyawa (1). Keempat puncak-puncak proton ekivalen tersebut yakni $\delta 1,21 \mathrm{ppm}(\mathrm{s}, 9 \mathrm{H}), 3,82 \mathrm{ppm}(\mathrm{s}$, 9H), 6,91 ppm (d, 6H, $J=8,3 \mathrm{~Hz}$ ), 7,42 ppm (d, $6 \mathrm{H}, J=8,3 \mathrm{~Hz}$ ). Total jumlah proton hasil

integrasi seperti tertulis dalam tanda kurung menghasilkan tigapuluh proton. Bila dihitung total jumlah proton pada senyawa (1) seperti yang tersaji pada Gambar 1 maka didapat sebesar tigapuluh proton. Hasil ini menunjukkan bahwa senyawa (1) hasil arilasi sesuai dengan hasil yang diharapkan. Tidak adanya puncak-puncak lain yang teridentifikasi pada spektra ${ }^{1} \mathrm{H}$ NMR menunjukkan bahwa tidak adanya pengotor yang menyebabkan ketidakmurnian senyawa (1) hasil arilasi. Selanjutnya dilakukan identifikasi terhadap senyawa (1) menggunakan ${ }^{13} \mathrm{C} N \mathrm{NM}$.

Spektra ${ }^{13} \mathrm{C}$ NMR yang tersaji pada Gambar 4 terlihat adanya tujuh puncak karbon ekivalen dengan sebarannya yakni pada $\delta 24,9$ ppm,
29,2 ppm, 55,0 ppm, 113,7 ppm, 128,0 ppm, 136,9 ppm, 160,0 ppm. Ketujuh karbon-karbon ekivalen tersebut yakni satu puncak untuk gugus metil pada $t$-butil germanium $\left(\mathrm{CH}_{3}\right)$, satu puncak untuk karbon kuartener pada $t$-butil germanium $(\mathrm{Cq})$, satu puncak karbon kuartener pada cincin aromatik (Cq), satu puncak karbon metin pada cincin aromatik $(\mathrm{CH})$, satu puncak karbon metin pada cincin aromatik $(\mathrm{CH})$, satu puncak karbon kuartener pada cincin aromatik ( $\mathrm{Cq})$ dan satu puncak metil pada gugus metoksi $\left(-\mathrm{OCH}_{3}\right)$. Untuk membedakan puncak-puncak karbon ekivalen tersebut maka dilakukan pengukuran DEPT135 NMR yang mengidentifikasikan puncak karbon primer, karbon sekunder, karbon tersier maupun karbon kuartener [13]. Spektra DEPT-135 NMR senyawa (1) disajikan pada Gambar 5.

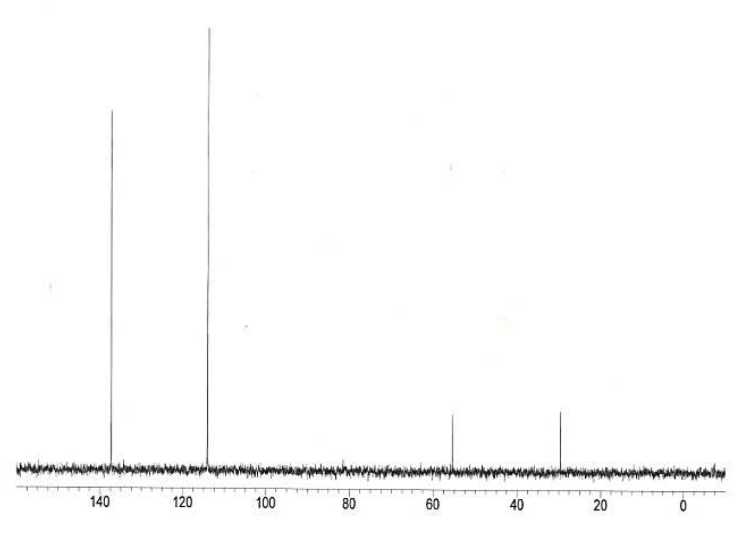

Gambar 5.

Spektra DEPT-135 NMR senyawa (1).

Pada spektra DEPT-135 NMR pada Gambar 5 dapat dibedakan ketujuh puncak-puncak karbon ekivalen tersebut yakni karbon primer muncul dengan puncak keatas dengan intensitas yang kecil, puncak puncak karbon sekunder dengan puncak yang mengarah kebawah, puncak kabon tersier yang muncul dengan intensitas yang tinggi dan puncak karbon kuartener yang tak muncul dari pengukuran. Spektra DEPT-135 NMR tersebut dibandingkan dengan spektra ${ }^{13} \mathrm{C}$ NMR dan didapat identifikasi karon-karbon pada 
senyawa (1) yakni $\delta 24,9 \mathrm{ppm}(\mathrm{Cq}), 29,2 \mathrm{ppm}$ $\left(\mathrm{CH}_{3}\right), 55,0 \mathrm{ppm}\left(\mathrm{CH}_{3}\right), 113,7 \mathrm{ppm}(\mathrm{CH}), 128,0$ ppm (Cq), 136,9 ppm (CH), 160,0 ppm (Cq). Hasil pengukuran ${ }^{13} \mathrm{C}$ NMR dan DEPT-135 NMR ini memperkuat bahwa senyawa (1) telah berhasil disintesis dari proses asilasi 4-iodida anisol dengan $t$-butil germanium membentuk tris(4-metoksifenil)t-butil germanium dengan struktur yang tersaji pada Gambar 1.

\section{Kesimpulan}

Dari hasil penelitian yang telah dilakukan maka dapat disimpulkan bahwa senyawa tris(4-metoksifenil)t-butil germanium (1) dapat disintesis melalui arilasi 4-iodida anisol dengan $t$-butil germanium menggunakan katalis paladium menghasilkan rendemen sebesar $35 \%$. Senyawa (1) mempunyai titik leleh $113,5-$ $114,5{ }^{\circ} \mathrm{C}, \mathrm{m} / \mathrm{z} 452,4$ puncak proton ekivalen, dan 7 puncak karbon ekivalen.

\section{UCAPAN TERIMA KASIH}

Disampaikan kepada Prof. Hiroshi Nishihara, The University of Tokyo atas fasilitas pengukuran menggunakan NMR dan GC-MS.

\section{Daftar Pustaka}

[1] Yabusaki.Y, Ohshima. N, Kondo. H, Kusamoto. T, Yamanoi. Y, Nishihara. H, Chemistry A European Journal (2010) 16, 5581-5585.

[2] Tsuji. J, Palladium Reagents and Catalyst (2004) Chichester, Wiley.

[3] Negishi. E, Organopalladium Chemistry (2002) New York, Wiley-Interscience.

[4] Trost. B. M, Verhoeven. T. R, Comprehensive Organometallic Chemistry (1982) Pergamon, Oxford, UK.

[5] Lesbani. A, Kondo. H, Yabusaki. Y, Nakai. M, Yamanoi. Y, Nishihara. H, Chemistry A European Journal (2010) 16, 13519-13527.

[6] Lesbani. A, Kondo. H, Yamanoi. Y, Nishihara. N, Jurnal Kimia FMIPA Universitas Udayana (2012) 6, 1-7.

[7] Lesbani. A, Kondo. H, Sato J. I, Yamanoi. Y, Nishihara. H, Chemical Communications (2010) 46, 7784-7786.

[8] Huheey. J. E, Keitler. R. L, Inorganic Chemistry (1983) Harper Collins Collage Publisher, New York.

[9] Shriver \& Atkins, Inorganic Chemistry, $4^{\text {th }}$ Edition (2006) Oxford University Press, UK.

[10] Szafran. Z, Pike R.M, Singh, M. M, Microscale Inorganic Chemistry (1991) John Willey and Sons, New York.

[11] Solomons. T.W.G, Fryhle. C.B, Organic Chemistry 9th Edition. (2008) John Wiley \& Sons, Inc, USA.

[12] Clayden, Greeves, Warren, Wothers, Organic Chemistry, Oxford University Press. (2008) Oxford, UK.

[13] Jones Jr. M, Organic Chemistry $3^{\text {rd }}$ edition (2005) W. W Norton \& Company Ltd, New York. 